\title{
Biology, affinity and description of an unusual aquatic new genus and species of Isotomidae (Collembola) from high altitude lakes in Tasmania
}

\author{
Penelope GREENSLADE ${ }^{1,2,3}$ and Mikhail POTAPOV ${ }^{4}$ \\ ${ }^{1}$ Department of Environmental Management, School of Science, Information Technology and Engineering, Federation University, \\ Ballarat, Victoria 3353, Australia; e-mail: pgreenslade@federation.edu.au \\ ${ }^{2}$ Department of Botany and Zoology, Australian National University, GPO Box Australian Capital Territory, 0200, Australia \\ ${ }^{3}$ South Australian Museum, North Terrace, Adelaide, South Australia 5000, Australia \\ ${ }^{4}$ Moscow State Pedagogical University, Department of Zoology and Ecology, Moscow 129164, Kibalchicha 6 B5, Russia; \\ e-mail: mpnk-abroad@yandex.ru
}

Key words. Collembola, Isotomidae, Chionobora amila, new genus, new species, Antarctica, diatoms, refugia, adversity selection

\begin{abstract}
A new species of Isotomidae (Collembola) was collected from submerged stones on the edge of nine lakes on Tasmania's Central Highland Plateau. Because it did not comply fully with the characters of any existing genus, a new genus, Chionobora gen. n. is erected for it here. An Antarctic species, Desoria klovstadi (Carpenter), has characters which conform with the new genus so is formally transferred to the new genus here. The Antarctic Continent and Tasmania were last in proximity 60 million years b.p. so it is suggested both species are relicts persisting in probable ice-free refugia during glacial cycles. Gut contents of specimens of the new species exclusively contained diatoms in various stages of digestion and the species appears to graze on aquatic macrophytes, a feeding habit not recorded before for Collembola. We note the high numbers of endemic invertebrate taxa of restricted distributions in cold habitats of southern regions compared to warmer regions and stress their conservation values and threats to their populations.
\end{abstract}

\section{INTRODUCTION}

In 1988, numerous individuals of a previously unknown species of Collembola were collected by Tasmanian aquatic biologists during a survey of the littoral fauna of highland lakes on the Great Lakes Plateau Superficially the species was similar in habitus and some characters to $\mathrm{Hy}$ droisotoma schaefferi (Krausbauer, 1898) from a similar habitat in North Hemisphere. Characters in common were cylindrical dens, claw and mucro as well as habitus, all of which are adaptations to an aquatic habitat (Deharveng \& Bedos, 2004) however it lacked bothriotricha which are a diagnostic character for Hydroisotoma.

In order to demonstrate the phylogenetic and biogeographical affinities of the new species, a new genus is erected for it, is diagnosed and its affinities discussed. It was found that Desoria klovstadi complied with the characters of the new genus rather than with Desoria sensu stricto so it is transferred formally to the new genus, Chionobora, here.

We also here discuss the paleogeographic reasons why high generic and high taxon diversity in Collembola and other invertebrates is found in severe habitats in the extreme south including Tasmania.

\section{METHODS}

The specimens were collected by removing submerged pebbles from the edge of the lake, turning them over and washing any organism adhering to the surface through a sieve of mesh size $500 \mu \mathrm{m}$ aperture, into a vessel containing $10 \%$ formalin and later preserved in $75 \%$ alcohol. A minimum of 20 rocks were sampled at each site.
ABBREVIATIONS: Abd - abdominal segments; Ant - antennal segments. PAO - post antennal organ, Th - thoracic segments. SAMA - South Australian Museum, Adelaide.

\section{RESULTS}

\section{Chionobora gen. $\mathbf{n}$.}

Type species. Chionobora amila sp. n. by present designation.

Diagnosis. Ocelli $8+8$, PAO present, simple. Ant 2 and 3 with many short, blunt, curved s chaetae both thick and thin. Subapical pin-chaeta of Ant 4 simple. Basomedian and proximal parts of labium polychaetotic. Maxillary head not modified, maxillary outer lobe with bifurcate palp and 2-4 sublobal hairs. Abd V and VI separate, Tibiotarsi with tenent hairs not clavate, T-chaetae partly lost. Furca long with many chaetae on anterior and posterior sides. Manubrium with ventroapical chaetae not differentiated. Dens regularly tapering, posterior side crenulate (klovstadi) or tuberculate (amila). Mucro slender, quadridentate.

Body covered with fine smooth chaetae, macrochaetae short or hardly differentiated, smooth. Glands at base of chaetae absent. Bothriotricha absent. Accp-s chaetae positioned exactly in p-row of chaetae on body tergites.

Etymology. Chion-cold, bora-south (Greek roots). Feminine.

Chionobora amila sp. $\mathrm{n}$.

Colour. Dark pigment in broad bands on body except for anterior part of abdomen VI.

Habitus. Head large, hypognathous, body stout (Fig. 1). Antennae about 1.5 times the diagonal of the head, ratio $5.5: 3.5$. Ratio of lengths of abdominal segments III to VI as $2.0-3.1: 1.8-2.6: 1.0-1.3: 1.0$ measured dorsally. 


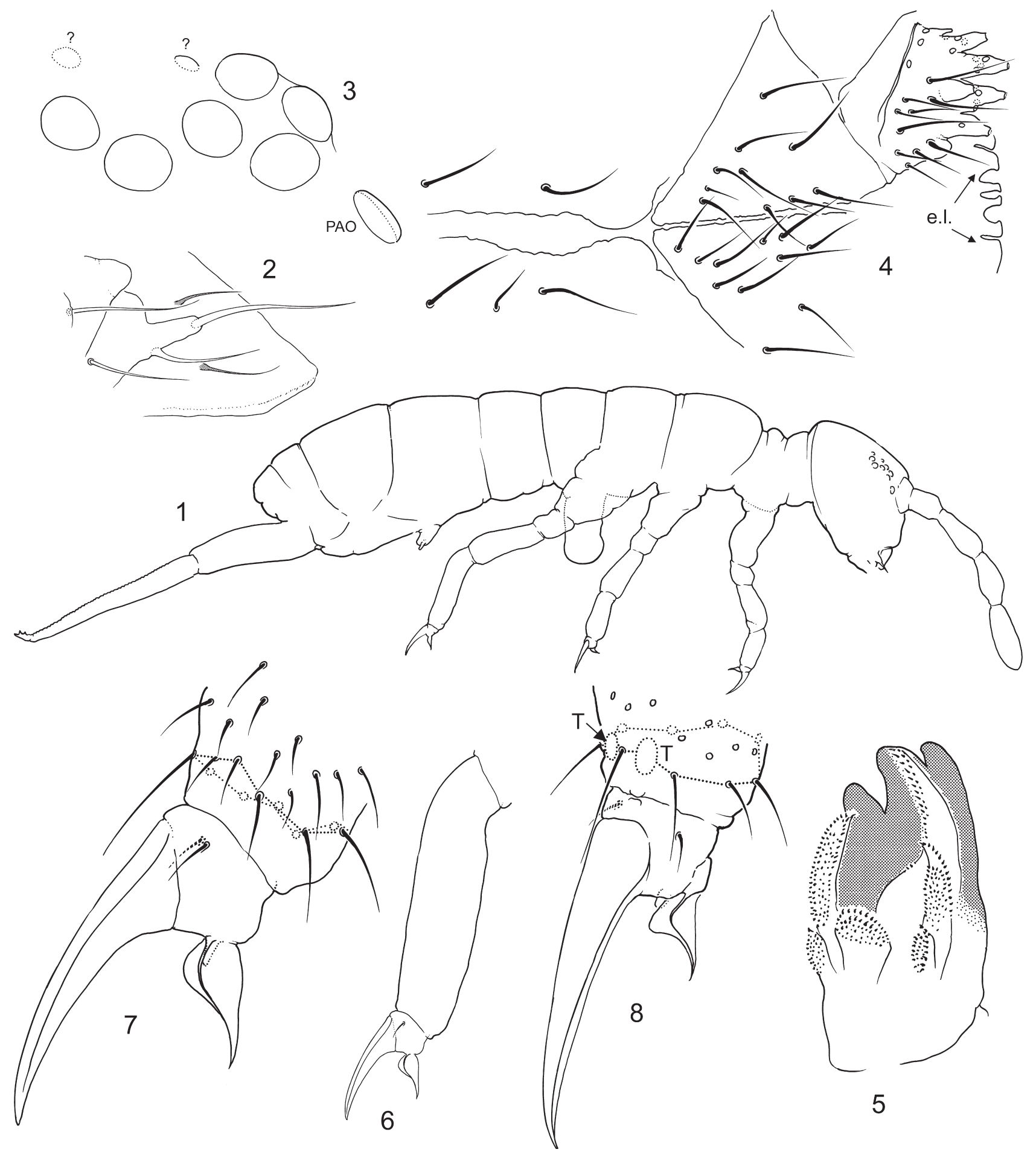

Figs 1-8: Chionobora amila sp. n. 1 - habitus; 2 - maxillary outer lobe; 3 - PAO and ocelli (the presence of ocelli G and $\mathrm{H}$ under question); 4 - ventral side of head, postlabial chaetae, labial palp and edge of labrum shown; 5 - maxillary head; 6-7 - distal half of leg 3; 8 - apical part of leg 2; e.l. - edge of labrum, T-T-chaetae.

Chaetotaxy. Plurichaetotic, body and appendages densely covered with short (but not equal), smooth, pointed chaetae (Fig. 9). Macrochaetae hardly developed, the longest chaetae of Abd V about 0.25 as long as this segment length. Bothriotricha absent; s chaetae well marked; shorter than common chaetae, number of s-chaetae in adult specimens on Th II-Abd V as 7-9 (6-8 accp + 1 al), 7-8 (6-7 accp +1 al)/7 (accp), 7-8 (accp), 7-9 (7-8 accp + 0-1 as), 8-10 (7-9 accp + 1 as), 7 (5 accp +2 as). Median s chaetae (as) always present on Abd IV and V, often absent on Abd IV. Accp-s chaetae located in p-row (not anterior to it), very rarely with one or two s chaetae in a segment slightly displaced to a more anterior position (Figs 9-10). Laterally positioned accp s chaetae thicker and shorter than others. Micro s chaetae 1,1/1,1,1 from thorax to abdomen III inserted anteriorly on all segments (Fig. 10).

Head and antennae. Antennal organ III with 2 inner cylindrical s chaetae distally and 2 outer more basal s chaetae, 


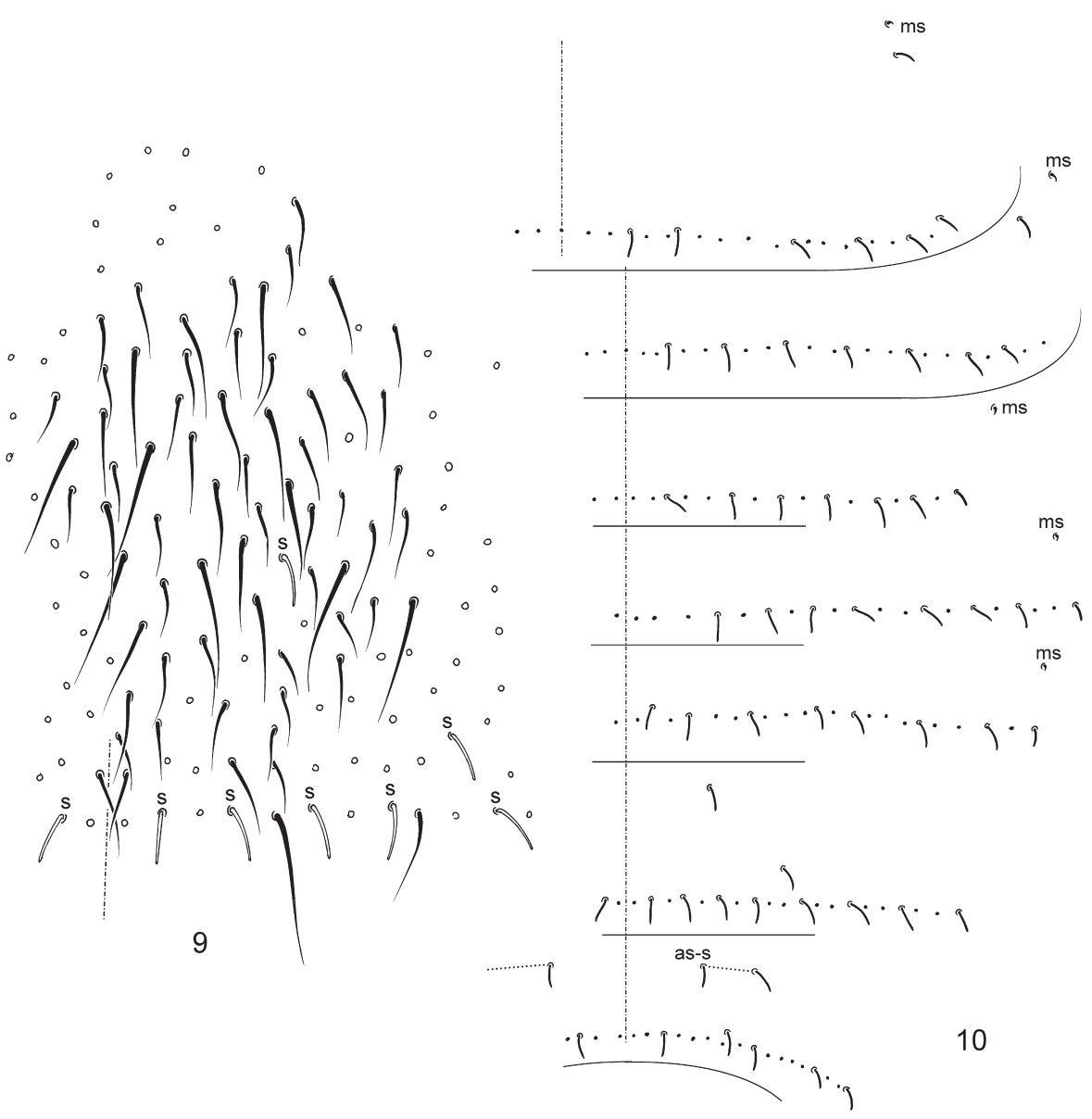

Figs 9-10: Chionobora amila sp. n. 9 - chaetal covering of median part of Abd IV; 10 - s chaetae chaetotaxy; as-s - as-s chaetae.

similar in shape. In addition, dorsal side of Ant III densely covered with numerous thin, short s chaetae in distal half; a compact group of thick cylindrical s chaetae inserted on outer edge (Fig. 12). Ant II with few both thin and thick s chaetae on outer edge (Fig 11). Ant I with a group (about 4) of basal microchaetae and short and thick s chaetae at middle section (usually 4 in number). Antennal segment IV with simple knob at tip and simple (not bifurcate) subapical pin-chaeta. Subapical organite small, round. Many s chaetae with curved tips occur on all antennal segments distally, and numerous thinner s chaetae. Antenna of male without specialised chaetae. Clypeal field with about 65 chaetae. Prelabral chaetae 4; labral chaetae all spine-like particularly distally and set in papillae, 5,5,4 in number. Anterior margin of labrum with rather broad apical folds (Fig. 4). Ocelli $8+8$, although $\mathrm{G}$ and $\mathrm{H}$ hardly visible. PAO small, simple, broadly oval, slightly longer than anterior ocelli. Maxilla not modified, with three teeth and six normal lamellae, not extending beyond the teeth, lamella 1 slender, with single row of cilia; other lamellae rather short (Fig. 5). Maxillary outer lobe with palp bifurcate, number of sublobal hairs varies from 2 to 3 (variant with 2 shown in Fig. 2). Labium with 8-11 basomedian, 8-11 proximal and 5 basolateral chaetae (Fig. 4). Labial palp unmodified, with full set of guards (16), lateral process small (Fig. 4).

Thorax. Tibiotarsus broad and flattened, shortest on leg 1 and 2 (Fig. 1). Claw long and thin, apparently without in- ner tooth although minute lateral teeth sometimes visible. Tenent hairs not clavate (Figs 6-8). Empodial appendage with lobe at base, broad, with 3 lamellae and no teeth. Nomenclature of chaetae in tibiotarsal distal row of tibiotarsi uncertain as masked by polychaetosis (basal set is $7 \mathrm{~A}$ chaetae and $4 \mathrm{~T}$-chaetae, but some chaetae can be displaced to distal row from the main part of tibiotarsi). Distal row with from 8 to 11 (maximum primitive number 11) with at least T1 and T2 chaeta absent in some specimens (Fig. 8).

Abdomen. Abd V and VI separate dorsally. Ventral tube with 8-11 + 8-11 latero-distal chaetae and about 7 chaetae posteriorly, 2 in distal transversal row (Fig. 13). Anterior chaetae absent. Furca long. Medial cleft of manubrium fairly distinct. Dens thick, slightly tapering, tuberculated on posterior side, with numerous chaetae on posterior and anterior sides (Figs 14, 16). Chaetae of posterior side short, covering from $1 / 2$ to $3 / 5$ of its length. Mucro stout, lamellate, without chaeta, with three teeth evenly spaced, fourth tooth smallest, developed as projection of outer lamella of third tooth (Figs 16-18); both second and third teeth have outer and inner lamellae, inner lamella of second tooth with four scallops (Figs 17-18). Ratio manubrium : dens : mucro = 7-11:12-17: 1; furcal subcoxae with about 32 and 100 chaetae respectively.

Female without spines on anal lobes, $2+2$ fine chaetae on genital opening. 


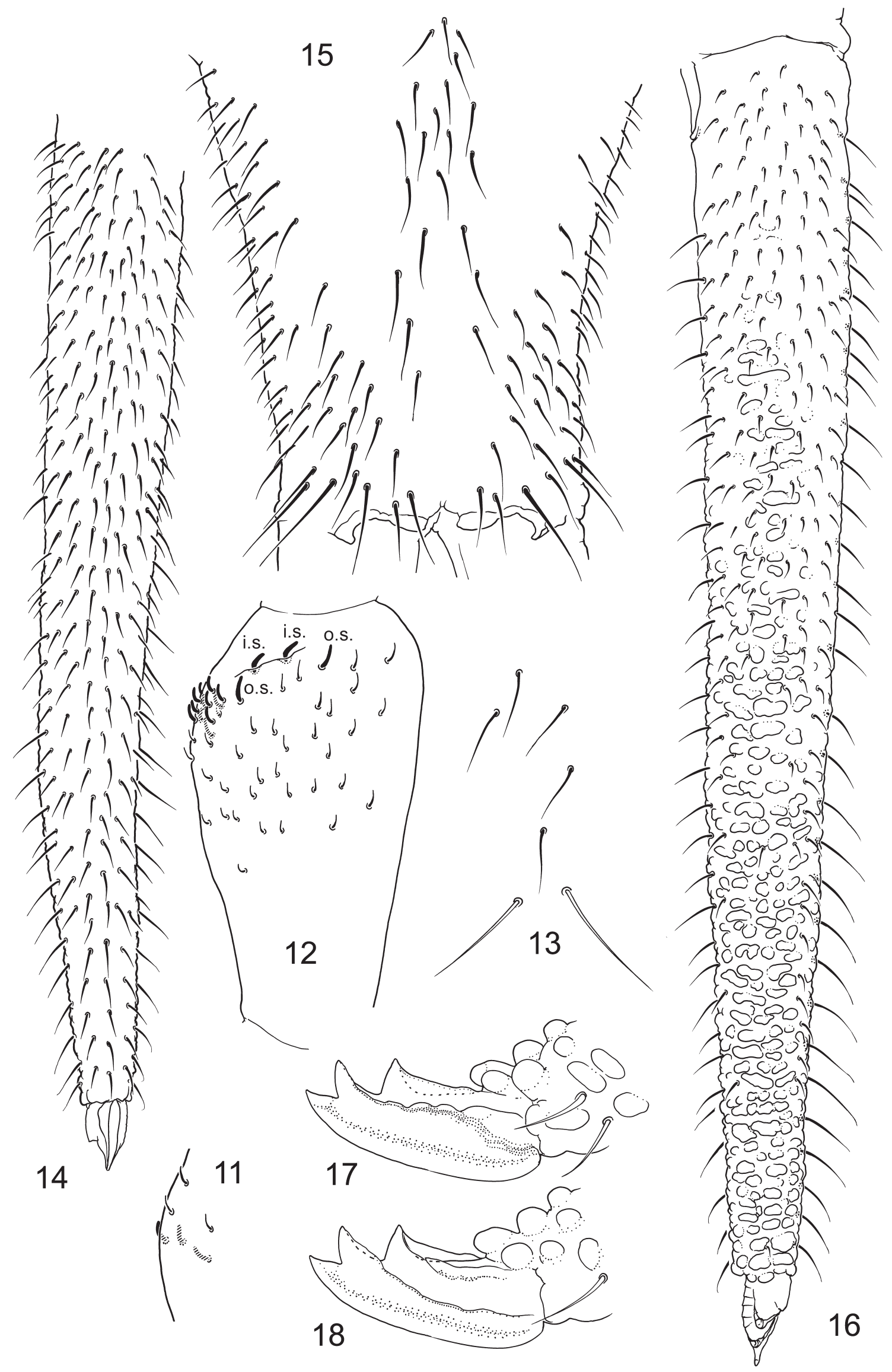

Figs 11-18: Chionobora amila sp. n. 11 - group of s chaetae in lateral part of Ant 2;12 - s chaetae of Ant 3, dorsal view; 13 - chaetae of posterior side of ventral tube; 14, 16 - dens, anterior (14) and posterior (16) view; 15 - manubrium, anterior view; 17, 18 - mucro, inner (17) and outer (18) views; i.s. and o.s. - inner and outer s chaetae of antennal organ. 
Type material. Holotype $\delta$ : Tasmania, Central Plateau: Lake Meander, Central Plateau, 1306, GR577714, under submerged stones at edge of lake; RM, 4.ii.1988 (SAMA registration number
I22637). Paratypes: Four slides with single female each, one slide with three females; all paratypes with same collecting data as the holotype.

TABLE 1. Comparison of morphological characters of fifteen taxa of Isotominae.

\begin{tabular}{|c|c|c|c|c|c|c|c|c|c|c|c|c|}
\hline Group / taxon & $\begin{array}{l}\exists \\
\overline{0} \\
\end{array}$ & $\begin{array}{l}\frac{n}{\pi} \\
\frac{0}{0} \\
\text { 0 } \\
\text { n }\end{array}$ & 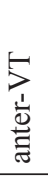 & 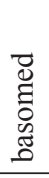 & 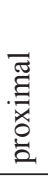 & 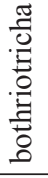 & 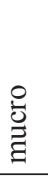 & $\begin{array}{l}\mathbb{\pi} \\
\frac{\pi}{0} \\
\frac{\pi}{0} \\
i \\
\end{array}$ & $\begin{array}{l}\stackrel{0}{\overparen{\pi}} \\
\frac{\pi}{0} \\
0\end{array}$ & $\begin{array}{l}\dot{\bar{d}} \\
\vec{w} \\
0 \\
0 \\
\dot{0} \\
\dot{n}\end{array}$ & 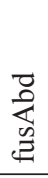 & $\begin{array}{l}\text { है } \\
\text { ज्ञ } \\
\text { }\end{array}$ \\
\hline Isotoma Bourlet, 1839 s. str. & 0 & 0 & 0 & 1 & 0 & 0 & 1 & 0 & 0 & 1 & 0 & 1 \\
\hline Desoria spp. gr. pjasini (Martynova, 1974) & 0 & 0 & 0 & 0 & 0 & 0 & 1 & 0 & 0 & 1 & 0 & 1 \\
\hline Pseudoisotoma Handschin, 1924 & 0 & 0 & 0 & 0 & 0 & 0 & 1 & 0 & 1 & 1 & 1 & 1 \\
\hline Folsomotoma Bagnall, 1949 & 1 & 0 & 0 & 0 & 0 & 0 & 1 & 0 & 0 & 0 & 1 & 1 \\
\hline Parisotoma Bagnall, 1940 & 1 & 0 & 0 & 0 & 0 & 0 & 1 & 0 & 0 & 0 & 0 & 0 \\
\hline Desoria trispinata (MacGillivray, 1896) & 0 & 0 & 0 & 0 & 0 & 0 & 1 & 0 & 0 & 0 & 0 & 0 \\
\hline Isotomurus Börner, 1903 s. str. & 0 & 0 & 0 & 1 & 1 & 1 & 0 & 0 & 0 & 1 & 0 & 0 \\
\hline Isotomurus antennalis Bagnall, 1940 & 0 & 0 & 0 & 1 & 1 & 0 & 0 & 0 & 0 & 1 & 0 & 0 \\
\hline Desoria Nicolet, 1941 s. str. 1 & 0 & 0 & 0 & 0 & 0 & 0 & 0 & 1 & 0 & 0 & 0 & 0 \\
\hline Desoria s. str. 2 & 0 & 0 & 0 & 0 & 0 & 0 & 0 & 1 & 0 & 1 & 0 & 0 \\
\hline Vertagopus Bagnall, 1939 & 0 & 0 & 0 & 0 & 0 & 0 & 0 & 1 & 1 & 0 & 0 & 0 \\
\hline Azoritoma macquariensis Greenslade \& Potapov, 2008 & 1 & 1 & 0 & 0 & 0 & 0 & 0 & 0 & 0 & 0 & 0 & 0 \\
\hline Chionobora amila sp. $\mathrm{n}$. & 0 & 1 & 1 & 1 & 1 & 0 & 0 & 0 & 0 & 0 & 0 & 0 \\
\hline Chionobora klovstadi (Carpenter, 1902) & 0 & 0 & 1 & 1 & 1 & 0 & 0 & 0 & 0 & 0 & 0 & 0 \\
\hline Granisotoma Cassagnau, 1957 s. str. & 0 & 0 & 1 & 0 & 0 & 0 & 0 & 1 & 0 & 1 & 0 & 0 \\
\hline
\end{tabular}

Character states used in phenetic analysis: 1 . ocelli: number of ocelli: normal at 6-8 (0), reduced number at $<5(1)$. 2. sblobals: number of sublobal hairs in maxillary outer lobe: normal number 4 (0), reduced number <4 (1). 3. anter-VT: chaetae on anterior side of VT: present (0), absent (1). 4. basomed: polychaetosis of basmedian group of chaetae in labium: $1=$ absent (0), $2=$ present (1). 5. proximal: polychaetosis of proximal group of chaetae in labium: absent (0), present (1). 6. ha: bothriotricha on body absent (0), present (1). 7. mucro: with 4 teeth (0), with 3 teeth (1). 8. T-chaetae: some of T-chaetae absent (0), all T-chaetae present (1). 9. clavatio: clavate tenent hairs absent (0), present (1). 10. s-poster: accp s chaetae on body tergites in p-row (0), in front of p-row (1). 11. fusAbd: Abd V and VI not fused (0), fused (1). 12. mansp: manubrial spines absent (0), present (1). Desoria s. str. 1 and 2 differ by accp s chaetae on body tergites situated in p-row or in front of p-row, respectively (see also Fig. 19).

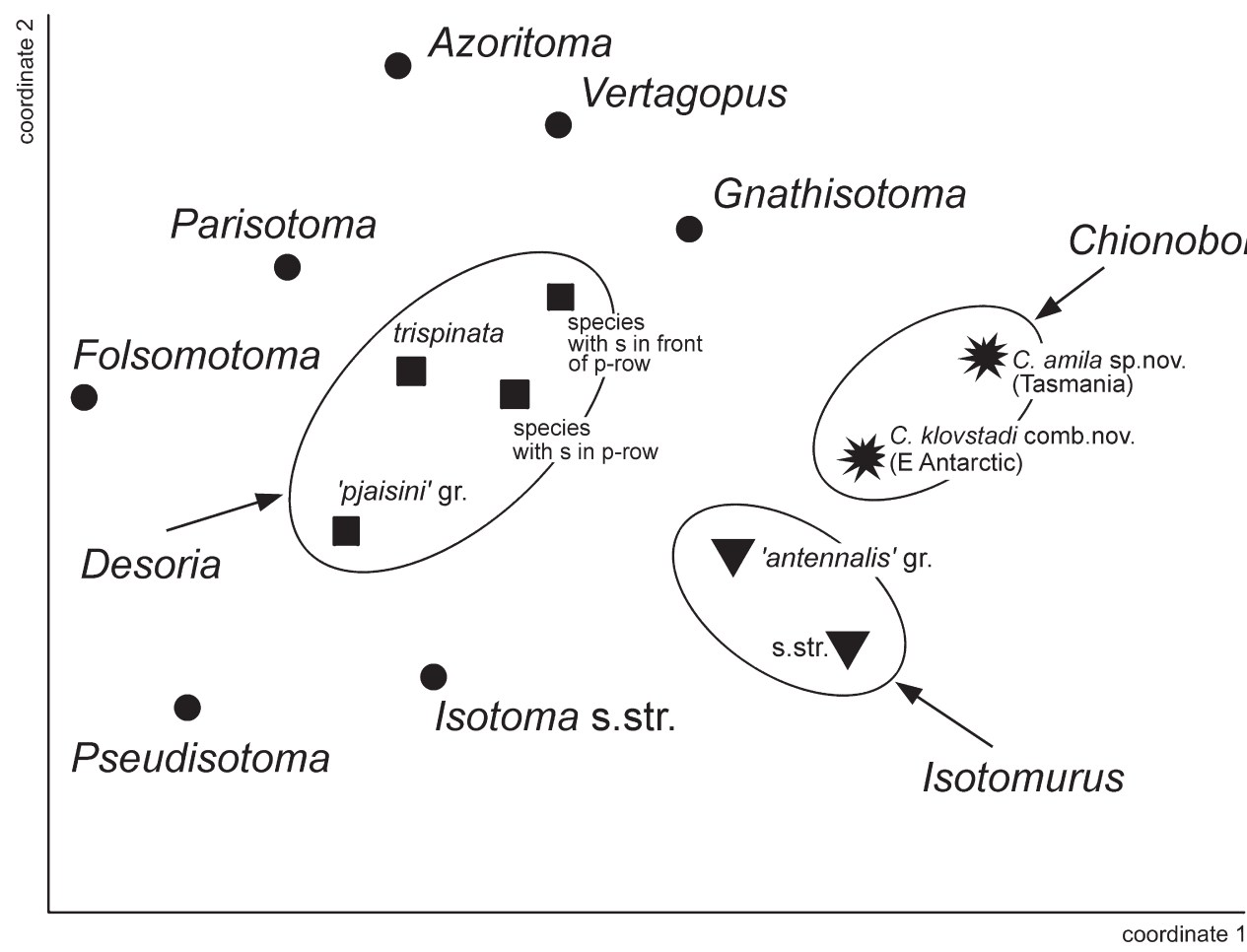

Fig. 19. Distance matrix of similarities between selected genera and southern species groups of Isotominae based on characters in Table 1. The programme PAST (Hammer et al., 2001) was used to perform non-metric multidimensional scaling basing on Euclidian distances matrix. The figure suggests that Chionobora gen. $\mathrm{n}$. may be most closely related and sister group to Isotomurus antennalis group. 

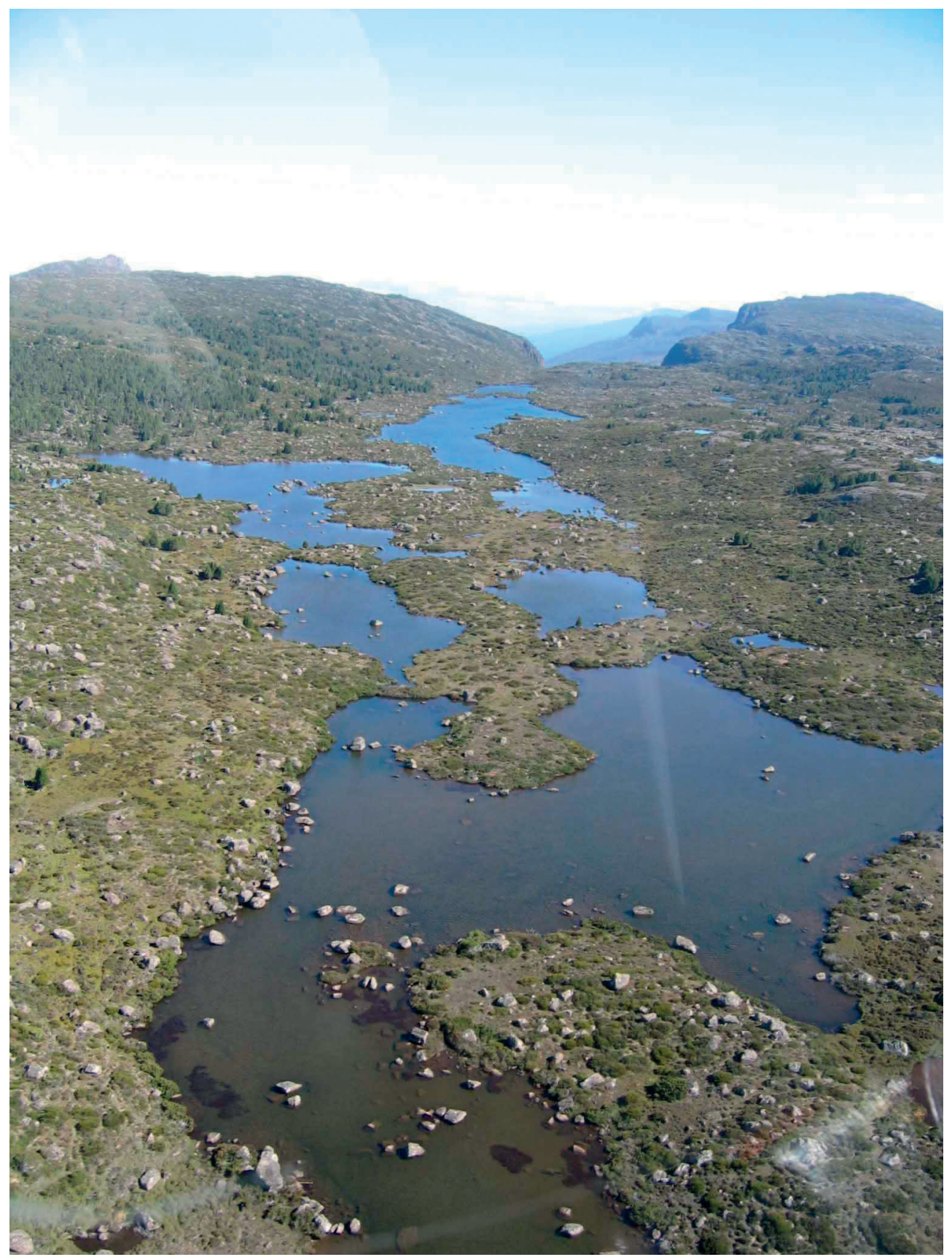

Fig. 20. Colour photograph of Long Tarns, taken by Karen Storey.

Other material examined (all Tasmania, SAMA). On slides: Lake Butters, $1240 \mathrm{~m}$ asl, GR483705, rock fauna, 6C/As, SC, 5.ii.1988 (1ठึ). In alcohol: Lake Toorah, $1170 \mathrm{~m}$ asl, GR393643 (5) RM; Lake Butters, GR483705 (7) SC; Triangle Lake, 1151 m asl, GR381585 (1) RM; Lake Naomi, 1015 m asl, GR476575 (1) RM: Lake Nive, 992 m asl, GR420499 (1) RM; Daisy Lake, 1270 m asl, GR452737 (1) SC; Lake Meander GR577714 (9+8 mounted) RM; Lunka Lake, 1200 m asl, GR507668 (1) SC; Long Tarns, 1270 m, GR463737 (4) PD. Collectors: R. McClaine (RM), S. Chilcott (SC), P. Davies (PD).

Etymology. Anagram of Alima (an Arabic word meaning water sprite or sea maiden).

Distribution. Only known from lakes on the Central Plateau of Tasmania.

Ecology. Chionobora amila sp. n. was collected by removing submerged or partially submerged stones from the edges of lakes and washing the surfaces of the rocks. The habitat is illustrated in Figs 20 and 21.

The species is living in an aquatic medium which is confirmed by examination of gut contents of some individuals, each of which contained numerous diatoms belonging to the genera Gomphonema, Navicola and Frustulia (Fig. 22). Gomphonema species are epiphytic and Frustulia are acidophilic. The $C$. amila sp. n. specimens collected appeared to graze exclusively on diatoms growing on epiphytes and, as the species has a grinding molar plate, is probably able to penetrate the silicon coating of the diatoms.

Remarks. Chionobora amila sp. n. cannot be placed into any existing genus of Isotomidae but it shares characters with several genera of Isotominae. The genus to which the new species is most closely approximated is the Northern 


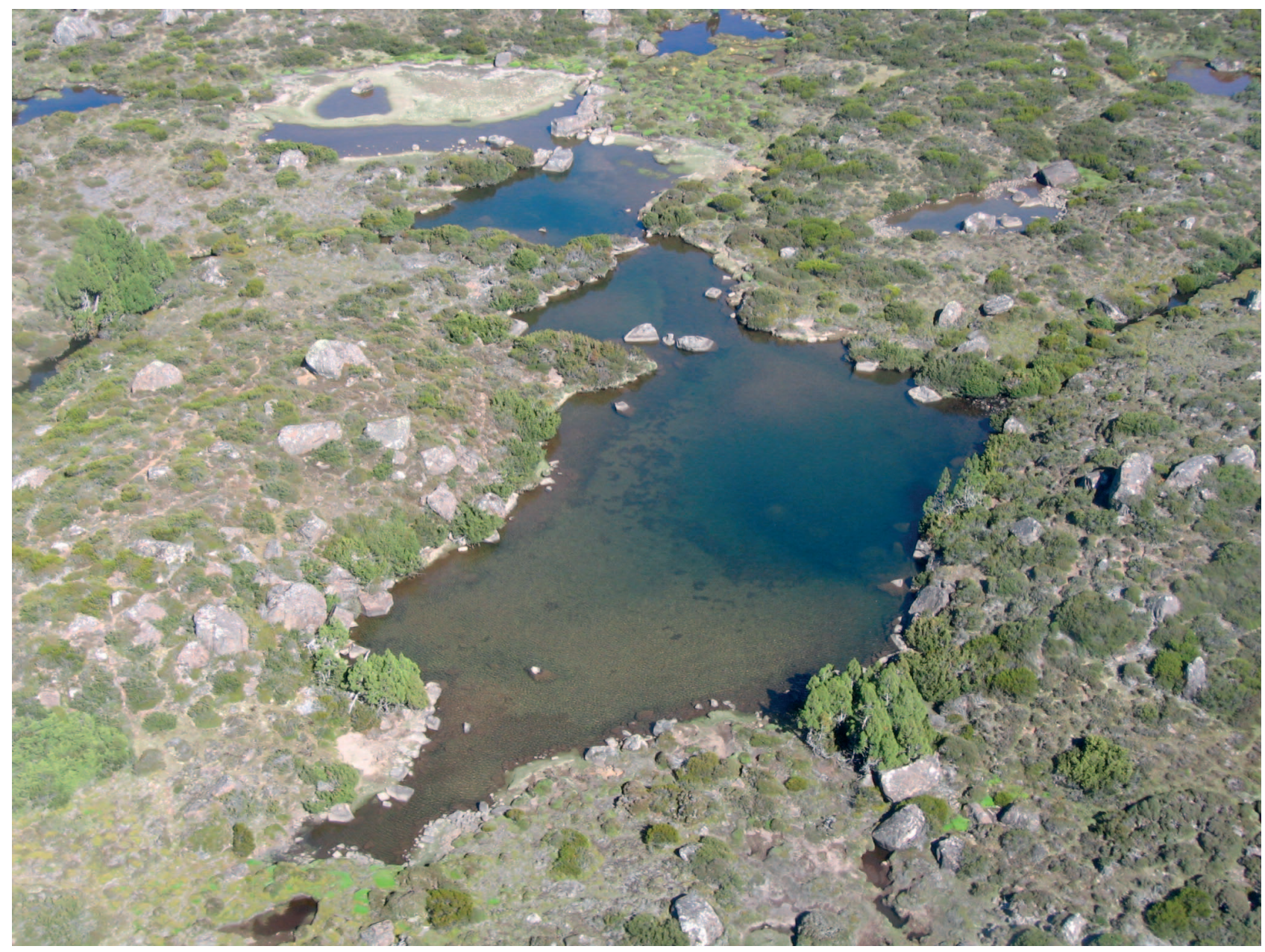

Fig. 21. Colour photograph of Daisy Lake, taken by Karen Storey.

Hemisphere Desoria Nicolet, 1841, although it differs in several diagnostic morphological characters for this genus. The only southern representatives of Desoria sensu stricto currently known from Australia are likely to be introduced. The exception is Desoria klovstadi (Carpenter, 1902) from the Antarctic, which was redescribed by Stevens et al. (2006) and noted as an aberrant member of the genus; it is herein transferred to the new genus Chionobora (see below). Significant characters can be grouped into three types as follows:

1. Characters that are adaptations to aquatic habitat. Subcylindrical tuberculated dens, massive lamellate mucro, slender claw, large hypognathous head, covering of short and numerous chaetae, flattened tibiotarsi and polychaetosis of labium (Deharveng \& Bedos 2002). The new species is morphologically similar to Hydroisotoma schaefferi only in characters that are adaptations to an aquatic habitat. Characters in common are: lamellate mucro, reduced number of sublobal hairs (absent in H. schaefferi), increased number of chaetae on labial palp and form of dens. The new genus differs from $H$. schaefferi in the absence of bothriotricha, absence of mucronal chaetae, absence of spines on female anal valves and tubercles on dens. The four species of another Holarctic genus, Granisotoma Stach, 1947, live in contact with cold water, have long, cylindrical, tuberculated dens and lamellate mucro, and manubrium in some species with numerous chaetae on anterior side (G. danilevskyi Martynova, 1968, G. sadoana Yosii, 1965) similar to the new genus. Granisotoma species, however, have chaetae on the mucro and labial baseis oligochaetotic. This last character has only been observed in the type species of the genus, G. rainieri (Folsom, 1937) but other species of Granisotoma are not well known so the position of the genus within Isotomidae is unclear. Two other semi-aquatic genera Agrenia Börner, 1906 (dens is always tuberculated) and Isotomurus Börner, 1903 (particularly species with tuberculated dens) have polychaetotic labia but both have other diagnostic differences, for example, a long subapical chaeta on dens and bothriotricha on body, respectively.

\section{Characters showing affinities with Southern Hemi-} sphere taxa. The presence of spiny or serrated chaetae on parts of furca and/or body is an important character in Isotominae genera of South Hemisphere. They are present in Tomocerura Wahlgren, 1901; Procerura Salmon, 1941; Paracerura Deharveng \& Oliviera, 1994 and Acanthomurus Womersley, 1934 among others. The new genus lacks this character. Although the new genus differs in external appearance and ecology, it shares the rare character of two sublobal hairs with the monotypic euedaphic genus Azoritoma Greenslade \& Potapov, 2008, described from within cushion plants on subantarctic Macquarie Island. 


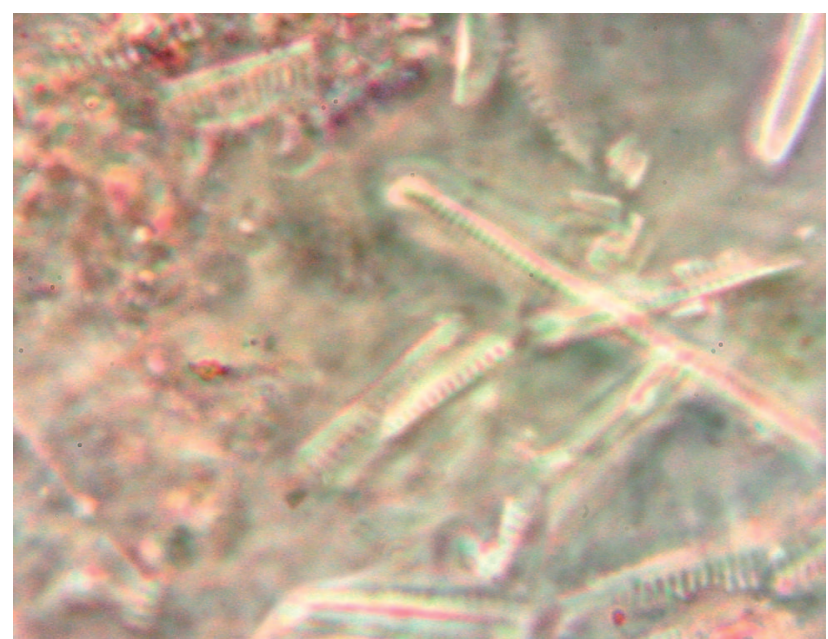

Fig. 22. Micrographs of gut contents of Chionobora amila sp. n. from Lake Meander, mid gut contents $\times 1000$, taken by I. Atazaheh.

Azoritoma possesses adaptations to an euedaphic way of life with loss of ocelli and pigment, as well as development of specialised s chaetae on Ant I and Abd V. Table 1 lists other characters that differ between these two genera. The unusual modification of mouthparts of Azoritoma is likely to be related to the specialised habitat in which it is found. The new genus also shows some morphological similarities with Tibiolatra Salmon, 1941, a genus living in a similar habitat in New Zealand, as both posses flattened tibiotarsi. However Tibiolatra has antennal segments III and IV subsegmented, is furnished with serrated chaetae on body and a dens with serrated spines.

3. Similarity to groups of Northern Hemisphere. The new taxon shows a few affinities with three, largely Northern Hemisphere, genera, Isotoma, Desoria and Isotomurus but it did not comply sufficiently to place the new species in any of the three. The relationships of these genera have been discussed in several papers (Deharveng, 1981; Potapov, 2002; Stevens et al., 2006). To graphically illustrate the currently known affinities of genera of Isotominae lacking dental spines, a phenetic scatter diagram in given in Fig. 19 using the characters listed in Table 1. The programme PAST (Hammer et al., 2001) was used to perform non-metric multidimensional scaling basing on Euclidian distances matrix. One hypothesis, based on a selection of characters, is that Chionobora gen. n. and Isotomurus antennalis group are possibly sister groups (Bagnall, 1940) (the group which has no bothriotricha).

Chionobora klovstadi (Carpenter, 1902) comb. n.

Isotoma klovstadi Carpenter, 1902: 222.

Desoria klovstadi: Stevens in Stevens et al., 2006: 822.

Desoria klovstadi, from East Antarctica, is the most closely related species to $C$. amila and complies with the diagnosis of the new genus. Both species combine two rare characters: absence of anterior chaetae on ventral tube and strong polychaetosis of labium. Other characters in common are: position of accp-s chaetae in p-row, form of mucro, short and numerous smooth chaetae on body, general shape of maxillary head rectangular and loss of some of Tchaetae on tibiotarsus. The Antarctic species however does not possess characters that are adaptations for species living in contact with water as does $C$. amila. The morphological characters of Desoria klovstadi placed the species in an intermediate position between the Northern Hemisphere Isotoma $\mathrm{s}$. str. and Desoria s. str. Nicolet, 1841 (Stevens et al., 2006). Sequence data did not indicate a close relationship of $D$. klovstadi with existing Isotominae genera. Stevens et al. (2006) therefore provisionally placed the species in Desoria. The affinity of D. klovstadi with the new genus is demonstrated here; consequently it is hereby transferred to Chionobora.

Material examined. East Antarctic, Cape Jones, 11.ii.2009. Collector F. Frati (10 individuals in coll. M. Potapov).

Distribution. Patchily distributed in Northern Victoria Land, Antarctic Continent.

\section{DISCUSSION}

The new genus has the unique combination of characters in Isotominae of polychaetotic labium, lack of bothriotricha on body, no anterior chaetae on ventral tube and some T-chaetae on tibiotarsi lost. Two species, $C$. amila and $C$. klovstadi are known to possess these characters; both are restricted to high latitudes of the Southern Hemisphere. Sequence data for C. klovstadi did not resolve any affinity with Northern Hemisphere genera so it is possible that molecular analysis for $C$. amila might be similarly not illuminating. Ancient phylogenetic relationships may not always be revealed from sequence data. It may be significant that Tasmania was last adjacent to the part of North Victoria Land, where C. klovstadi occurs, 60 million years ago (Royer \& Rollet, 1997).

The current climate of the Central Plateau is cold, windy and can be both wet and dry according to season. Annual rainfall here can vary from 3000 to $1000 \mathrm{~mm}$ from northwest to east. Average maximum temperatures are $18.7^{\circ} \mathrm{C}$ in summer and $5.5^{\circ} \mathrm{C}$ in winter while minimums are from $-2^{\circ} \mathrm{C}$ in winter and $5.5^{\circ} \mathrm{C}$ in summer. (Storey \& Comfort, 2007). Consequently both species of Chionobora live in extreme habitats, that is they are A- (adversity) selected and also possess a range of adaptive characters, typical for the habitat in which they are found. Correlates of adversity selection are given in Greenslade (1983) and include selection against dispersal if adapted to stable but predictably severe environments which may explain their restricted distributions. It is therefore most likely that vicariance and not dispersal is the cause of species divergence in this genus.

Glaciation on the plateau has occurred multiple times over the last two million years but it is believed the area west of Lake Augusta, where C. amila occurs, remained ice free and that alpine vegetation was present (Kieran, 1990; Colhoun et al., 1996; Kirkpatrick \& Fowler, 1998). Shiel et al. (1998) note that at times these lakes "may have been refugia for aquatic species". Stevens et al. (2006) suggested that C. klovstadi is a relict persisting in Northern Victoria land (Eastern Antarctica) in refugia throughout glacial 
periods and Stevens et al. (2006) detected multiple glacial refugia for Chionobora in Northern Victoria Land. This could also be proposed for $C$. amila with both Chionobora species surviving with limited change over a long period in extremely cold habitats in stasis. This proposes an alternative strategy to (Fraser et al., 2014) who suggested, based on biodiversity modelling, that geothermal sites allowed species to persist throughout glacial cycles.

The geological formation on which $C$. amila occurs is part of a large area of Jurassic dolerite over nearly half of Tasmania. This rock type cracks as it cools and later becomes eroded resulting in a plethora of crevices providing protected refuges for invertebrates.

There are over 3000 lakes and tarns in the Central Highlands. The survey during which C. amila was found, sampled 120 lakes (Fulton, 1998) but C. amila was only found on nine of them. These lakes are all fairly small, within 25 $\mathrm{km}$ of each other and at an altitude of between 1000 and $1200 \mathrm{~m}$ in the southern part of the Plateau. Two are shown in Figs 20 and 21.There appears to be no apparent reason for $C$. amila being only found in a few of the lakes surveyed but there are a number of possible reasons such as incomplete sampling, paleohistorical factors, fire both accidental and managed, algal composition, as well as past grazing by stock and road construction leading to erosion into the lake and recreation (Storey \& Comfort, 2007). It is known that the Plateau lakes are heavily used for trout fishing and that trout have been introduced to most lakes with some lake levels manipulated for hydroelectric schemes (Anon., 2002; Storey \& Comfort, 2007). Also trout are known to impact deleteriously on aquatic invertebrates (Cadwallader, 1996; Davies et al., 2002; Elvey, 2002), however all but one lake (Meander) contained trout at the time of sampling (S. Chilcott, pers. com.). Most individuals of C. amila were found in Lake Meander.

Other examples of invertebrate aquatic taxa with endemic species and genera in the Central Highlands region are the fresh water aquatic invertebrates of Rotifera (Shiel et al., 1998); Mollusca (Ponder et al., 1993), Annelida (Pinder \& Brinkhurst, 2000), phreatoicoid Isopoda (Knott, 1975), Ephemeroptera (Campbell, 1988) (see Greenslade \& New, 1991). An additional threat to this fauna is that it is predicted that the region will experience reduced rainfall with climate change. The preservation and protection of such faunas, that provide information on the palaeohistory of habitats and faunas present today is clearly of a high priority.

ACKNOWLEDGEMENTS. Thanks are due to the staff of the Tasmanian Fisheries Authority who collected and supplied the specimens, to S. Chilcott and M. Driessen for supplying valuable background information, to I. Atazaheh for identifying and photographing the diatoms and to F. Frati for supplying specimens of D. klovstadi. M. Potapov received financial support from the Ministry of Education and Science of the Russian Federation (Project No. 6.632.2014/K).

\section{REFERENCES}

Anon. 2002: Western Lakes Fishery Management Plan. Inland Fisheries Service, Tasmania, 44 pp.
CAdwallader P.L. 1996: Overview of the Impacts of Introduced Salmonids on Australian Naive Fauna. Australian Nature Conservation Agency, Canberra, 68 pp.

CAmpbell I.C. 1988: Ephemeroptera. In Houston W.W.K. (ed.): Zoological Catalogue of Australia. Ephemeroptera, Megaloptera, Odonata, Plecoptera, Trichoptera. Vol. 6. Australian Government Publishing Service, Canberra, pp. 1-22, 284-286.

Carpenter G. 1902: Aptera: Collembola. Chapter 9 Insecta. In: The Report on the Collections of Natural History Made in the Antarctic Regions during the Voyage of the Southern Cross. British Museum (Natural History), London, pp. 221-223.

Colhoun E.A. 2002: Periglacial landforms and deposits of Tasmania. - Sth Afr. J. Sci. 98: 55-45.

Davies P.E., Cook L.S.J., Elvey W., Sloane T., Warfe D., Lewis G. ET AL. 2002: Montreal Indicator: Testing and Refinement of AUISRIVAS for the Detection and Assessment and Interpretation of Changes in Stream Biodiversity Associated with Forestry Operations. Report to Forest and Wood Products Corporation, Hobart, Tasmania, $126 \mathrm{pp}$.

Deharveng L. \& Bedos A. 2004: Insecta: Collembola. In Yule C.M. \& Yong H.S (ed.): Freshwater Invertebrates of the Malaysian Region. Academy of Sciences Malaysia and Monash University, Kuala Lumpur, pp. 384-393.

Elvey W.F. 2002: The Impacts of Brown Trout (Salmo trutta) in Streams: The Implications of Prey Identity and Habitat. Unpublished PhD thesis, University of Tasmania, Hobart, 140 pp.

Fraser C.I., Terauds A., Smellie J., Convey P. \& Chown S.L. 2014: Geothermal activity helps life survive glacial cycles. Proc. Natl. Acad. Sci. U.S.A. 111: 5634-5639.

Fulton W. 1998: The Freshwater Fish Fauna of Tasmania's Central Plateau. Inland Fisheries Commission, University of Tasmania, Hobart, 80 pp.

Greenslade P. 1985: Conservation Priorities in Tasmania's Nonmarine Invertebrates. Unpublished report to Tasmanian Parks and Wildlife Service, Hobart, 169 pp.

Greenslade P. \& New T.R. 1991: Australia: conservation of a continental insect fauna. In Collins N.M. \& Thomas J.A. (eds): The Conservation of Insects and their Habitats. Proceedings of the Royal Entomological Society's 15th Symposium 14-15th September 1989. Academic Press, London, pp. 33-70.

Greenslade P. \& Potapov M. 2008: A new genus and species of Isotominae (Collembola: Isotomidae) from cushion plants on subantarctic Macquarie Island. — Kanunnah 2: 87-97.

Kiernan K. 1990: The extent of lae Cenozoic glaciation in the central highlands of Tasmania. - Arctic Alpine Res. 22: 341354.

KirKPATRICK J.B. \& Fowler M. 1998: Locating likely glacial refugia in Tasmania using palynolgical and ecological information to test alternative climatic modes. - Biol. Conserv. 85: 171-182.

KnotT B. 1975: Systematic Studies on the Phreatoicoidea (Order Isopoda) with a Discussion on the Phylogeny and Zoogeography of other Freshwater Malacostracan Crustaceans from Australia and Tasmania. Unpublished PhD Thesis, University of Tasmania, Hobart.

OAMmer Ø., HARPer D.A.T. \& RYAN P.D. 2001: PAST: Paleontological statistics software package for education and data analysis. - Palaeontol. Electron. 4(1): 9 pp.

Pinder A.M. \& Brinkhurst R.O. 2000: A review of the Tubificidae (Annelida: Oligochaeta) from Australian inland waters. - Mem. Mus. Victoria 58: 39-75.

Ponder W.F., Clark G.A., Miller A.C. \& Toluzzi A. 1993: On a major radiation of freshwater snails in Tasmania and eastern Victoria: a preliminary overview of the Beddomeia group 
(Mollusca: Gastropoda: Hydrobiidae). - Invert. Taxon. 7: 501-750.

ROYeR J.-Y. \& Rollet N. 1997: Plate tectonic setting of the Tasmanian region. - Austral. J. Earth Sci. 44: 543-560.

SALmon J.T. 1941: The collembolan fauna of New Zealand, including a discussion of its distribution and affinities. - Trans. R. Soc. N. Z. 70: 282-431.

Shiel R.J., Koste W. \& Tan L.W. 1989: Tasmania revisited: rotifer communities and habitat heterogeneity. - Hydrobiologia 186-7: 239-249.

Smith B.J. \& Kershaw R.C. 1981: Tasmanian land and fresh water molluscs. Fauna of Tasmania Handbook. Vol. 5. University of Tasmania, Hobart, 148 pp.

Stach J. 1947: The Apterygotan Fauna of Poland in Relation to the World Fauna of this Group of Insects. Polish Academy of Sciences, Krakow, 488 pp.
Stevens M.I., Fuellberg A., Greenslade P., Hogg I.D. \& SunNUCKS P. 2006: Redescription of the Antarctic springtail, Isotoma klovstadi suggests greater distinctiveness of the Antarctic fauna. - Polar Biol. 29: 820-830.

Stevens M.I., Frati F., Mcgaughran A., Spinsanti G. \& Hogg I.D. 2007: Phylogeographic structure suggests multiple glacial refugia in northern Victoria Land for the endemic Antarctic springtail Desoria klovstadi (Collembola, Isotomidae). Zool. Scripta 36: 201-212.

Storey K. \& Comfort M. 2007: A Progress Report on the Development of Rehabilitation Priorities for Brad Scale Erosion within the World Heritage Area on the Central Plateau of Tasmania. Nature Conservation Report 07/01, DPIW, Hobart.

Received August 30, 2014; revised and accepted December 4, 2014 Prepublished online February 3, 2015 